\title{
Monoamine oxidase A (MAOA) gene polymorphism in offenders and psychiatric patients in an Egyptian Study
}

\author{
Ahmed M. M. Galal El-Din ${ }^{1}$, Nagwa Hassan Ali ${ }^{1}$, Hamdy Hamed Swelim ${ }^{1}$, \\ Khalda Said Amr ${ }^{2}$, and Laila Kamal El-Din Effat ${ }^{2}$ \\ ${ }^{1}$ (Department of Zoology, Faculty of Science, Ain Shams University, Cairo, Egypt) \\ ${ }^{2}$ (Department of HUMAN Molecular Genetics, National Research Center, Dokki, Egypt)
}

\begin{abstract}
Functional characterization studies revealed that transcriptional activity of the human monoamine oxidase A (MAOA) gene is modulated by a polymorphic repetitive sequence located in $1.2 \mathrm{~kb}$ upstream of the ATG codon. To investigate the possible influence of the allelic variants of the MAOA gene (MAOA) on the genetic predisposition to aggressive behavior, a case-control association study of 50 psychiatric patients and 50 offenders, as well as 50 healthy controls was conducted. Statistical analysis showed no significant differences in allele or genotype frequencies between control and patient groups. Our results revealed that high significant difference was observed when comparing the 5-repeat allele frequency in psychiatric patients with control $(P=$ 0.0001). Although there is no association between MAOA genotype and susceptibility to psychiatric disorder, and offending in the studied groups. Taken together, these findings suggest that either high or low activity alleles of the MAOA-uVNTR 30-bp polymorphism are not associated with antisocial behavior in offenders or psychiatric patients.
\end{abstract}

Keywords: monoamine oxidase A; promoter polymorphism; antisocial behavior; psychiatric; offending.

\section{Introduction}

Aggression is considered as a positive symptom in many neuropsychiatric disorders. Genetic predispositions to violence, alcoholism, antisocial personality disorder, and other associated traits in criminal trials has been attributed to a genetic basis but specific genotyping evidence has been introduced on an extremely limited basis [1, 2]. Attention-deficit hyperactivity disorder (ADHD), mood disorders, and in particular bipolar disorders/pediatric mania, schizophrenia, conduct disorder, and borderline personality disorders, are most notably characterized by aggressive behavior [3, 4, and 1]. There is strong evidence that genes play a significant role in antisocial behavior and aggression. Psychosocial influences can result in structural modifications in DNA that have profound influences on neuronal functioning and hence antisocial behavior outcome [5]. On the basis of different pharmacological and genetic studies various neurotransmitters, hormones, cytokines, enzymes, growth factors, and signaling molecules have been associated with aggression [6]. Several studies in humans and animals have associated monoamine oxidase (MAO) with aggression [7, 8]. MAO is known as mitochondrial enzyme that catalyzes the oxidative deamination of neurotransmitters serotonin, dopamine and noradrenaline, which are involved in the regulation of aggressive behavior. The gene encoding MAOA is located on the Xp11.23-p11.4 chromosome [9] containing a polymorphism (MAOAuVNTR) located $1.2 \mathrm{~kb}$ upstream of the MAOA coding sequences. MAOA-uVNTR polymorphism consisting of a 30-base pair repeated sequence [10]. Six allele variants containing 2, 3, 3.5, 4, 5, or 6 repeats copies have been identified [11]. These different uVNTR variants are associated with different transcriptional activities of the MAOA promoter, which in turn result in different expression levels of the MAOA gene. In terms of expression, the MAOA gene was divided into two groups: a low MAOA activity group and a high MAOA activity group. The low MAOA activity group consisted of the 2, 3, and 5 repeats alleles, whereas the high MAOA activity group consisted of the 3.5-repeat allele and the 4-repeat allele [12]. The low activity alleles were found to be associated with aggression and impulsivity [13, 14]. However, Manor et al. [15] observed the high activity alleles were associated with ADHD [14, 16, 17and 18]. It has been further emphasized that, individuals having the low activity form of the gene that encodes monoamine oxidase A (MAOA-L) are more likely to show aggression when provoked or challenged [19, 20]. In psychiatric patients the low activity MAOA and early life trauma paradigm may also serve as one of the risk factors of physical aggression [21]. The aim of this study was to investigate the association of DNA variants of MAOA gene polymorphism with aggressive behavior in the offenders and psychiatric patients. 


\subsection{Subjects}

\section{Materials and Methods}

The study included 150 subjects. Fifty defendants were prosecuted for murder or attempted murder, as well as other serious offenses. Fifty psychiatric patients and 50 healthy individuals (without any previous convictions or psychiatric disorder) were included in the study. It was conducted in accordance with the Declaration of Helsinki and all subjects participated after giving informed consent.

\subsection{Genotyping}

Genomic DNA was isolated from buccal cells using the BioRobot EZ1 and EZ1 DNA extraction kits according to the instructions from the manufacturer (Qiagen Inc, Valencia, CA). Amplification of the MAOA uVNTR was performed according to Nilsson et al. [22]; the forward primer, 5'-AC AGC CTG ACC GTG GAG AAG-3' and the reverse primer 5'-GAA CGG ACG CTC CAT TCG GA-3'. The PCR reactions was performed on a GeneAmp $9700^{\circledR}$ with the following cycling condition: $95^{\circ} \mathrm{C}$ for 60 seconds, $35 \times\left(95^{\circ} \mathrm{C}\right.$ for 60 seconds, $63.5^{\circ} \mathrm{C}$ for 60 seconds and $72^{\circ} \mathrm{C}$ for 90 seconds) and final extension $72^{\circ} \mathrm{C}$ for 5 minutes. The PCR products were analyzed by electrophoresis of a $2 \%$ agarose gel staining with ethidium-bromide.

\subsection{Statistical analysis}

Statistics were performed using SPSS Software (Statistical Package for Social Sciences, Version 17.0; SPSS Inc., Chicago, IL, USA). Differences between genotype frequencies were tested using the $\chi^{2}$ test. Analyses were calculated by comparing allele frequencies in control group versus criminal and psychiatric groups.

\section{Results}

The MAOA-uVNTR in the promoter region was genotyped in all samples. Five alleles 3, 3.5, 4, 5, and 6 repeats of the $30 \mathrm{bp}$ sequence were identified for the MAOA-uVNTR in our samples. The six repeat allele of the MAOA-uVNTR was found in only one sample in the offender group so, it was excluded from the statistical analyses due to its low frequency. The allele distributions of the MAOA-uVNTR in the offenders, psychiatric patients, and control subjects are given in Table (1). It worth noticed that, the 5-repeat allele appeared once in both offenders and controls, although was observed in a high frequency in the psychiatric patients group (30\%) with highly significant difference $(P=0.0001)$.

Table (1): MAOA-uVNTR allele distributions among the offenders, psychiatric patients, and control groups

\begin{tabular}{|c|c|c|c|}
\hline \multirow{2}{*}{ Alleles } & \multicolumn{3}{|c|}{ Groups } \\
\hline & Offenders & Psychiatric patients & Control \\
\hline 3-repeats & $8(16 \%)$ & $10(20 \%)$ & $16(32 \%)$ \\
\hline$\chi^{2}$ & 2.66 & 1.38 & \\
\hline$P$-value & $0.102^{\mathrm{ns}}$ & $0.24^{\mathrm{ns}}$ & \\
\hline 3.5-repeats & $6(12 \%)$ & $1(2 \%)$ & $4(8 \%)$ \\
\hline$\chi^{2}$ & 0.40 & 1.80 & \\
\hline$P$-value & $0.53^{\text {ns }}$ & $0.18^{\text {ns }}$ & \\
\hline 4-repeats & $35(70 \%)$ & $23(46 \%)$ & $29(58 \%)$ \\
\hline$\chi^{2}$ & 0.563 & 0.69 & \\
\hline$P$-value & $0.45^{\mathrm{ns}}$ & $0.405^{\mathrm{ns}}$ & \\
\hline 5-repeats & $1(2 \%)$ & $15(30 \%)$ & $1(2 \%)$ \\
\hline$\chi^{2}$ & 0 & 12.25 & \\
\hline$P$-value & $1.0^{\mathrm{ns}}$ & $0.0001^{* * *}$ & \\
\hline
\end{tabular}

***: Very highly significant at $\mathrm{P}<0.05$ ns: not significant.

In terms of expression, $34 \%$ of controls had the MAOA-L activity allele (2, 3, and 5 repeat) and $66 \%$ had the MAOA-H activity allele (3.5 and 4). The distribution of the MAOA-L and MAOA-H activity in offenders was 18 and $82 \%$, respectively, while in psychiatric patients was 50 and $48 \%$, respectively (Table 2). No significant difference was observed in case of psychiatric patients and offenders group when compared to control as shown in (Table 2). 
Monoamine oxidase A (MAOA) gene polymorphism in offenders and psychiatric patients in an...

Table (2): MAOA high and low activity allele's frequencies in offenders, psychiatric patients, and control groups

\begin{tabular}{|c|c|c|c|}
\hline \multirow{2}{*}{ MAOA activity } & \multicolumn{3}{|c|}{ Groups } \\
\cline { 2 - 4 } & Offenders & Psychiatric patients & Control \\
\hline High-activity & $41(82 \%)$ & $24(48 \%)$ & $33(66 \%)$ \\
\hline$\chi^{2}$ & 0.86 & 1.42 & \\
\hline$P$-value & $0.35^{\mathrm{ns}}$ & $0.23^{\mathrm{ns}}$ & $17(34 \%)$ \\
\hline Low-activity & $9(18 \%)$ & $25(50 \%)$ & \\
\hline$\chi^{2}$ & 2.46 & 1.52 & \\
\hline$P$-value & $0.11^{\mathrm{ns}}$ & $0.22^{\mathrm{ns}}$ & \\
\hline$P<0.05$ ns: not significant & &
\end{tabular}

\section{Discussion and Conclusion}

The VNTR polymorphism in the MAOA promoter has five alleles containing 2, 3, 3.5, 4, and 5 copies of a 30-bp tandem repeat. In terms of expression, the MAOA gene is divided into two groups: a low MAOA activity group and a high MAOA activity group. The low MAOA activity group consists of the 2, 3, and 5 repeats alleles, whereas the high MAOA activity group consists of the 3.5-repeat allele and the 4-repeat allele [5]. The short allele was found to be associated with aggression and impulsivity [13, 14]. Manor et al. [15] observed that the longer alleles were associated with ADHD [16, 17]. The results of our study revealed that repeat units 3 and 4 are to be the most common alleles in all studied samples, the 2-repeat allele was not observed, and presence of only one variant with 6 copies of a 30-bp repeat in the offender group. The 4-repeat allele was found in high frequency in all tested samples; this might be due to the presence of genetic background of males Egyptian ancestry (A.F. in all tested samples= 58\%). Also, the 4-repeat allele was also reported to be the most frequent in Caucasian Australians [23], American individuals (60.5\%) [24], Caucasian with European ancestry population (74\%) [25], and in Whites and African American populations (62.80\% and 45.50\%, respectively) [26]. However, the 5-repeat allele was observed in a high frequency only in the psychiatric patients and was significantly different compared to the control $\left(\chi^{2}=12.25, P=0.0001\right)$, suggesting possible association with aggression in this group. This finding was inconsistent with Guimarães et al. [27] who observed the 5repeat allele in low frequency in boys with attention deficit hyperactivity disorder $(0.02 \%)$. Also Lung et al. [28] found that the 5-repeat allele had a low frequency ( $0.54 \%$ in males) with major depressive disorder. In addition, a low frequency of the 5-repeats allele was also observed in females with panic disorder [29].

The relationship between the MAOA uVNTR polymorphism and antisocial behaviour is still controversial. We found no significant difference in the MAOA-L activity either in offenders or psychiatric patients compared to control $(P=0.11$ and 0.22 , respectively). There was consistency with previously published results of different groups of different psychiatric disorder and offenders reporting no significant difference in MAO-L activity [30, 31, and 32] where the $P$-value was greater than $0.05(P=0.555,0.624$, and 0.967 , respectively).

Moreover, no significant difference was observed in either offenders or psychiatric patients with MAOA-H activity compared to control $(P=0.35$ and 0.23 , respectively). These results were consistent with previously published studies on either patients with various psychiatric disorders or individuals with a history of delinquency $[12,33,34,35,36,26,37,38$, and 39] where no significant difference was obtained $(P>0.05$, ranged from $0.170-0.44)$.

So, in conclusion, this study indicates that psychiatric patients with 5-repeat unit have a higher risk of developing aggression. Preventive management could be considered for these high risk groups by early therapeutic intervention considering environmental factors. 


\section{References}

[1] S. S. Lee, Deviant peer affiliation and antisocial behavior: interaction with monoamine oxidase A (MAOA) genotype. J. Abnorm. Child. Psychol.; 39, 2011, 321-332.

[2] P. R. Butovskaya, M. L. Butovskaya, V. A. Vasilyev, O. E. Lazebny, D. V. Shibalev, E. V. Veselovskaya, I. V. Udina, and A. P. Ryskov, Molecular-genetic polymorphisms of dopamine, serotonin and androgenic systems as molecular markers of success in judo wrestling sportsmen. J. Bioanal. Biomed.; S3, 2013, 005. doi:10.4172/1948-593X.S3-005.

[3] N. Perroud, P. Baud, D. Mouthon, P. Courtet, and A. Malafosse, Impulsivity, aggression and suicidal behavior in unipolar and bipolar disorders. J. Affect. Disord. 134, 2011, 112-118.

[4] M. Soyka, Neurobiology of aggression and violence in schizophrenia. Schizophr. Bull.; 37(5), 2011, $913-920$.

[5] A. Raine, Biosocial studies of antisocial and violent behavior in children and adults: A review. Journal of Abnormal Child Psychology, 30(4), 2002, 311-326.

[6] K. M. Beaver, M. DeLisi, M. G. Vaughn, and J. C. Barnes, Monoamine oxidase A genotype is associated with gang membership and weapon use. Comp. Psychiatry 51(2), 2010, 130-134.

[7] A. Takahashi, I. M. Quadros, R. M. De Almeida, and K. A. Miczek, Behavioral and pharmacogenetics of aggressive behavior. Curr. Top. Behav. Neurosci.; 12, 2012 73-138.

[8] C. Márquez, G. L. Poirier, M. I. Cordero, M. H. Larsen, A. Groner, J. Marquis, P. J. Magistretti, D. Trono, and C. Sandi, Peripuberty stress leads to abnormal aggression, altered amygdala and orbitofrontal reactivity and increased prefrontal MAOA gene expression. Transl. Psychiatry, 3(e216), 2013, doi:10.1038/tp.2012.144.

[9] L. Ozelius, Y. P. Hsu, G. Bruns, J. F. Powell, S. Chen, W. Weyler, M. Utterback, D. Zucker, J. Haines, J. A. Trofatter, Human monoamine oxidase gene (MAOA): chromosome position (Xp21-p11) and DNA polymorphism. Genomics, 3(1), 1988, 53-58.

[10] S. Z. Sabol, S. Hu, and D. Hamer, A functional polymorphism in the monoamine oxidase A gene promoter. Hum. Genet; 103, 1998, 273-9.

[11] R. Tikkanen, F. Ducci, D. Goldman, M. Holi, N. Lindberg, J. Tiihonen, and M. Virkkunen, MAOA alters the effects of heavy drinking and childhood physical abuse on risk for severe impulsive acts of violence among alcoholic violent offenders. Alcohol Clin. Exp. Res.; 34(5), 2010, 853-860.

[12] J. Kim-Cohen, A. Caspi, A. Taylor, B. Williams, R. Newcombe, I. W. Craig, and T. E. Moffit, MAOA, maltreatment, and geneenvironment interaction predicting children's mental health: new evidence and a meta-analysis. Molecular Psychiatry, 11, 2006, 903913.

[13] S. B. Manuck, J. D. Flory, R. E. Ferrell, J. J. Mann, and M. F. Muldoon, A regulatory polymorphism of the monoamine oxidase-A gene may be associated with variability in aggression, impulsivity, and central nervous system serotonergic responsivity. Psychiatry Res.; 95(1), 2000, 9-23.

[14] D. C. Lawson, D. Turic, K. Langely, H. M. Pay, C. F. Govan, N. Norton, M. L. Hamshere, M. J. Owen, M. C. O'Dononan, and A Thapar, Association analysis of monoamine oxidase A and attention deficit hyperactivity disorder. Am. J. Med. Genet. Part B. Neuropsych. Genet.; 116B(1), 2003, 84-89.

[15] I. Manor, S. Tyano, E. Mel, J. Eisenberg, R. Bachner-Melman, M. Kotler, and R. P. Ebstein, Family-based and association studies of monoamine oxidase A and attention deficit hyperactivity disorder (ADHD): preferential transmission of the long promoter-region repeat and its association with impaired performance on a continuous performance test (TOVA). Mol. Psychiatry; 7, 2002, 626-632.

[16] K. Domschke, K. Sheehan, N. Lowe, A, Kirley, C. Mullins, R. O'Sullivan, C. Freitag, T. Becker, J. Conroy, M. Fitzgerald, M. Gill, and Z. Hawi, Association analysis of the monoamine oxidase A and B genes with attention deficit hyperactivity disorder (ADHD) in an Irish sample: Preferential transmission of the MAO-A $941 \mathrm{G}$ allele to affected children. Am. J. Med. Genet. Part B: Neuropsych. Genet.; 134B(1), 2005, 110-114.

[17] M. Das, A. D. Bhowmik, S. Sinha, A. Chattopadhyay, K. Chadudhuri, M. Singh, and K. Mukhopadhyay, MAOA promoter polymorphism and attention deficit hyperactivity disorder (ADHD) in Indian children. Am. J. Med. Genet. Part B: Neuropsych. Genet.; 141B(1), 2006, 637-642.

[18] X. Xu, K. Brookes, C.-K. Chen, Y.-S. Huang, Y. Y. Wu, and P. Asherson, Association study between the monoamine oxidase A gene and attention deficit hyperactivity disorder in Taiwanese samples. BMC Psychiatry, 7, 2007, 10-14.

[19] A. Raine, From genes to brain to antisocial behavior. Antisocial Behavior, 17(5), 2008, 323-328.

[20] R. McDermott, D. Tingley, J. Cowden, G. Frazzetto, D. D. Johnson, Monoamine oxidase A gene (MAOA) predicts behavioral aggression following provocation. Proc. Natl. Acad. Sci. USA; 106, 2009, 2118-2123.

[21] G. Frazzetto, G. D. Lorenzo, V. Carola, L. Proietti, E. Sokolowska, A. Siracusano, C. Gross, and A. Troisi, Early trauma and increased risk for physical aggression during adulthood: the moderating role of MAOA genotype. PLoSONE, 2(5), 2007, e486.

[22] K. W. Nilsson, R. L. Sjoberg, M. Damberg, J. Leppert, J. Ohrvik, and P. O. Alm, Role of monoamine oxidase A genotype and psychosocial factors in male adolescent criminal activity. Biol. Psychiatry, 59, 2006, 121-127.

[23] A. F. Jorm, A. S. Henderson, P. A. Jacomb, H. Christensen, A. E. Korten, B. Rodgers, X. Tan, and S. Easteal, Association of a functional polymorphism of the monoamine oxidase A gene promoter with personality and psychiatric symptoms. Psychiatr. Genet.; 10, 2000, 87-90.

[24] S. P. Hamilton, S. L. Slager, G. A. Heiman, F. Haghighi, D. F. Klein, S. E. Hodge, M. M. Weissman, A. J. Fyer, and J. Knowles, No genetic linkage or association between a functional promoter polymorphism in the monoamine oxidase-A gene and panic disorder. Mol. Psychiatry, 5, 2000, 465-6.

[25] J. W. Buckholtz, J. H. Callicott, B. Kolachana, A. R. Hariri, T. E. Goldberg, M. Genderson, M. F. Egan, V. S. Mattay, D. R. Weinberger, and A. Meyer-Lindenberg, Genetic variation in MAOA modulates ventromedial prefrontal circuitry mediating individual differences in human personality. Mol. Psychiatry, 13(3), 2007, 313-324.

[26] I. M. Reti, J. Z. Xu, J. Yanofski, J. McKibben, M. Uhart, Y.-J. Cheng, P. Zandi, O. J. Bienvenu, J. Samuels, V. Willour, L. KaschSemenza, P. Costa, K. Bandeen-Roche, W. W. Eaton, and G. Nestadt, Monoamine oxidase A regulates antisocial personality in whites with no history of physical abuse. Comp. Psychiatry, 52(2), 2011, 188-194.

[27] A. P. Guimarães, C. Zeni, G. Polanczyk, J. P. Genro, T. Roman, L. A. Rohde, and M. H. Hutz, MAOA is associated with methylphenidate improvement of oppositional symptoms in boys with attention deficit hyperactivity disorder. International Journal of Neuropsychopharmacology, 12, 2009, 709-714.

[28] F.-W. Lung, D.-S. Tzeng, M.-F. Huang, and M.-B. Lee, Association of the MAOA promoter uVNTR polymorphism with suicide attempts in patients with major depressive disorder. BMC Medical Genetics, 12, 2011, 74-85. 
[29] A. Reif, H. Weber, K. Domschke, B. Klauke, C. Baumann, C. P. Jacob, A. Ströhle, A. L. Gerlach, G. W. Alpers, P. Pauli, A. Hamm, T. Kircher, V. Aroly, H.-U. Wittchen, E. B. Binder, A. Erhardt, and J. Deckert, Meta-analysis argues for a female-specific role of MAOA-uVNTR in panic disorder in four European populations. Am. J. Med. Genet. Part B, 2012, 1-8.

[30] C. P. Jacob, J. Muller, M. Schmidt, K. Hohenberger, L. Gutknecht, A. Reif, A. Schmidtke, R. Mossner, and K. P. Lesch, Cluster B personality disorders are associated with allelic variation of monoamine oxidase A activity. Neuropsychopharmacology, 4, $2005,1-8$.

[31] R. Tikkanen, R. L. Sjöberg, F. Ducci, D. Goldman, M. Holi, J. Tiihonen, and M. Virkkunen, Effects of MAOA-Genotype, Alcohol Consumption, and Aging on Violent Behavior. Alcohol Clin. Exp. Res.; 33(3), 2009, 428-434.

[32] M. Pardini, F. Krueger, C. Hodgkinson, V. Raymont, C. Ferrier, D. Goldman, M. Strenziok, S. Guida, and J. Grafman, Prefrontal cortex lesions and MAO-A modulate aggression in penetrating traumatic brain injury. Neurology, 76(12), 2011, 1038-1045.

[33] K. Malmberg, H.-L. Wargelius, P. Lichtenstein, L. Oreland, and J.-O. Larsson, ADHD and disruptive behavior scores-associations with MAO-A and 5-HTT gene and with platelet MAO-B activity in adolescents. BMC Psychit.; 8, 2008, 28-37.

[34] Davis, L. K.; Hazlett, H. C.; Librant, A. L.; Nopoulos, P.; Sheffield, V. C.; Piven, J.; and Wassink, T. H. (2008). Cortical enlargement in autism is associated with a functional VNTR in the monoamine oxidase A gene. Am. J. Med. Genet. B Neuropsychiatr. Genet.; 147B(7): 1145-1151.

[35] R. L. Sjöberg, F. Ducci, C. S. Barr, T. K. Newman, L. Dell'Osso, M. Virkkunen, and D. Goldman, A non-additive interaction of a functional MAO-A VNTR and testosterone predicts antisocial behavior. Neuropsychopharmacology, 33(2), 2008, 425-430.

[36] D. M. Fergusson, J. M. Boden, L. J. Horwood, A. L. Miller, and M. A. Kennedy, MAOA, abuse exposure and antisocial behavior: 30-year longitudinal study. BJP, 198, 2011, 457-463.

[37] V. Nikulina, C. S. Widom, and L. M. Brzustowicz, Child abuse and neglect, MAOA, and mental health outcomes: a prospective examination. Biol. Psychiatry, 71(4), 2012 350-357.

[38] R. McDermott, C. Dawes, E. Prom-Wormley, L. Eaves, and P. K. Hatemi, MAOA and Aggression A Gene-Environment Interaction in Two Populations. Journal of Conflict Resolution, 00(0), 2012, 1-22. doi: 10.1177/0022002712457746.

[39] Y. Kuepper, P. Grant, C. Wielpuetz, and J. Hennig, MAOA-uVNTR genotype predicts interindividual differences in experimental aggressiveness as a function of the degree of provocation. Behavioral Brain Res.; 247, 2013, 73-78. 